\title{
THE GAME AS THE CENTRAL ELEMENT OF INTERACTIVE AND SOCIAL SYSTEMS FOR THE TRANSFORMATION OF THE URBAN ENVIRONMENT
}

\author{
Author(s) : \\ Antonio OPROMOLLA ${ }^{1,2}$ \\ ${ }^{1}$ PhD Student in Interaction Design \\ ISIA Roma Design \\ ${ }^{2}$ Research Assistant \\ Link Campus University of Rome \\ anto.opro@gmail.com \\ Mauro PALATUCCI \\ Professor in Interaction Design \\ ISIA Roma Design \\ mauro.palatucci@gmail.com \\ Alessandro SPALLETTA \\ Professor in Product Design \\ ISIA Roma Design \\ alessandro.spalletta@isiaroma.it
}

\begin{abstract}
:
The "game" can be considered as a meta-design element useful for the emergence of collaborative processes and of new properties in the urban environment. These elements cause a transformation of the urban environment. In addition to the verbal languages, also the non-verbal languages can be used by citizens/players as performative "utterances" that allow both to communicate with the others and to create, to build, and to renovate. In this context, a systemic continuity among game, social systems, and architectural elements can be identified.
\end{abstract}

\section{Keywords :}

architecture, collaboration, game theory, meta-design, non-verbal languages, processes of emergence, relations, self-design, social systems, systemic continuity, urban transformation

\section{INTRODUCTION}

In this paper we firstly focus on the different processes of transformation of the urban environment. Although these processes are in most cases top-down, that is to say that they are imposed by Public Administrations without considering the specific people needs and desires, in some cases they can emerge directly through the action of people living the territory (they are called "city users").

Secondly, we focus on the characteristics of the "game", emphasizing how different authors, belonging to different disciplinary areas, have applied its characteristic elements in order to improve some human processes. We point the attention on how it is applied in the urban environment and the outcomes of this action. For example, we note that the application of the game in a territory causes first of all an interruption of the systemic continuity of the same territory, since it leads people to stop, to interact with specific elements of the urban environment and with other people, and also to change their mood. Considering the social item of the game, we argue that it can be used as a metaphor of the decision-making processes, by referring to the mathematical Game Theory, and on this basis, it can be applied to the processes of interaction among city users aiming to the moulding of the territory, in other words to the transformation of the urban environment. 
Then, we investigate the languages used for the interaction among city users, focusing not so much on the verbal languages, but on the non-verbal languages (for example: the kinesic system, the proxemic, etc.) since they represent some tools of "relation" among people which structure in different ways the spaces. For this reason they can be considered as "performative utterances". Since also the game is based on different non-verbal languages, it can be seen as a framework useful to structure the relationship and the environment.

In this sense, the game can be considered as a meta-design framework that allows to use verbal and non-verbal languages in order to co-create architectural elements, to transform the urban environment and to build relationships among city users. Indeed, the game is composed of different elements (e.g.: experience points, badges, missions, levels, awards, progression bar, gifts, etc.) that can be used individually or in combination in order to co-create and/or bring people. An analysis of four examples follows: 1) a square that becomes a game table in which the different players, carriers of different instances, collaborate in order to find the organization of the space that satisfies everyone; 2) a neighbourhood that becomes a role playing game where all their inhabitants and merchants play a role and complete the assigned "missions", dealing with the territory; 3) the whole city that becomes a drawing board, where people can imagine a new urban environment; 4) a bus stop that becomes a recreation ground that allows to build a relationship among people.

At the end, we emphasize how the application of the game elements in the urban environment brings out the systemic continuity among game, social systems, and architectural elements.

\section{THE PROCESSES OF TRANSFORMATION OF THE URBAN ENVIRONMENT}

\section{The Top-Down Environmental Transformation Process}

The process of transformation of the urban environment can be firstly intended as a top-down process, since the Public Administrations implement independently specific solutions within the territory. An example of this process is the construction of specific architectural elements in the urban environment only on the basis of technical needs and requirements of the territory. Although the role of the Public Administrations is carrying out public works for the advantage of the community, the whole community or a part of it may have different interests. This element may cause a real conflict. In most cases, the Public Administrations can only note that, without changing their plans, according to the technical and strategic requirements of the territory. However, in other situations, it would be possible to have a greater involvement of city users in the process of urban transformation.

\section{The "Self-Design" of The Urban Environment}

In most cases the process of the transformation of the environment can take place directly through the action of people. Indeed, according to Minati, 2001, the new properties of a system emerge from the interaction among the different elements of the same system. If one considers a city as a system and all the different people living in the territory as their basic elements, the interaction among them can be seen as an opportunity for the continuous emergence of new systemic properties of the city. In this way, the interaction allows to create a network which re-organizes the system. This process leads to a transformation of the space. In details, the exchanges among people who have different needs and intentions and their use of the territory, according to their different characteristics, cause the creation of new or renovated architectural elements in the urban environment. This act can be conscious, for example if there is a more or less structured decision making process, involving also the Public Administrations, or unconsious, for example if the daily use of a territory leads to its slow transformation over the time. A simple example of the latter are the "desire lines" emerged from the study of Throgmorton \& Eckstein, 2000, which describe the journeys across the city from people which do not take into account the official routes established. About that, De Certeau (2001) emphasizes the difference between "place" and "space": the first term concerns instantaneous 
configurations where everything is in its place, while the second term concerns the place practiced and used by people.

According to Minati, 2008, the outcome of this process can be considered as an act of "self-design". Indeed, the people build the territory in which they live, adapting it to the different needs. In this way the city build people's lives. This idea is consistent with the concept of "autopoiesis" of Maturana and Valera, 1980. According to these authors, such a system continually redefines, sustains, and reproduces itself. The process at the basis of these systems creates, processes and destroys it. It allows to maintain its proper organization and to produce its basic elements that recursively produce these elements. In the urban environment, the single elements, that are within the system, are: people, their relations, their needs, and their objectives.

In this process of self-design, where the Public Administrations are always present, the city users assume a mesoscopic point of view, because they are neither too close the territory (since they design it, they do not use it), nor too far from the territory (that is the point of view of the Public Administrations, which do not really "use" the territory). On the contrary, this process may bring city users and Public Administrations, giving the first the opportunity to design the territory in accordance with their needs and desires, and the second to let emerge the individuality and the specific nature of the territory.

\section{THE GAME AND THE TRANSFORMATION OF THE URBAN ENVIRONMENT}

The "game" is the basis of the work of different authors, belonging to different disciplinary sectors, who considered it as an element with specific characteristic enabling or improving some human processes. For example, Huizinga, 1971 considers the game as a central element in the human culture since it represents a requirement in the processes of civilization and knowledge. Moreover, Turner, 1982 focuses on the game as a useful tool for the world representation and invention. Finally, Mead, 1934 and Winnicott, 1971 consider the game as a key element in the self-perception of the single person, since it makes people aware of the presence of the Other. Concerning the urban environment, Alexander et al., 1977, in defining the patterns of interaction between the people and the territory, consider the game as a basic elements of the environments, focusing on the importance of urban spaces dedicated to playful activities.

In these examples, the game is commonly considered as an opportunity that reveals new attributes of a subject. In this paragraph we focus on the game as a central element in the urban environment, both since it allows to identify the systemic discontinuity of the spaces, and since it can be placed at the basis of the processes of interaction among people living in a specific territory.

\section{The Game as the Element Interrupting the Systemic Continuity of the Territory}

The game can be intended as an element interrupting the systemic continuity of the territory. Indeed, the different playful activities in the territory break the texture of the city, since it leads people to stop, to interact with specific elements of the urban environment and with other people, and also to change their mood. In this way, the place and the specific elements of the urban environments, take on new meaning. Above all, we refer to the punctual and almost unconscious acts of game, not to the conscious ones. Indeed, if the latter are represented by the spaces explicitly dedicated to the game (for example: a playground, an amusement park, a football pitch, etc.), some processes are on the contrary less explicit. Some examples are: the hopscotch game, where the traditional urban elements are used with other purposes; the parkour, where the movement of players surpasses the traditional urban physical elements; the buskers, who perform only if the viewer donates a coin. These examples reinvigorate and enrich the urban space, conducting the city users to a meta-reflection on the city.

The Figure 1 refers to the fountains of Piazza Gae Aulenti in Milan. They represent a tool of interaction with the people and in particular an affordance that drives people to touch the water and get wet, breaking in this way the linearity of the people paths. 


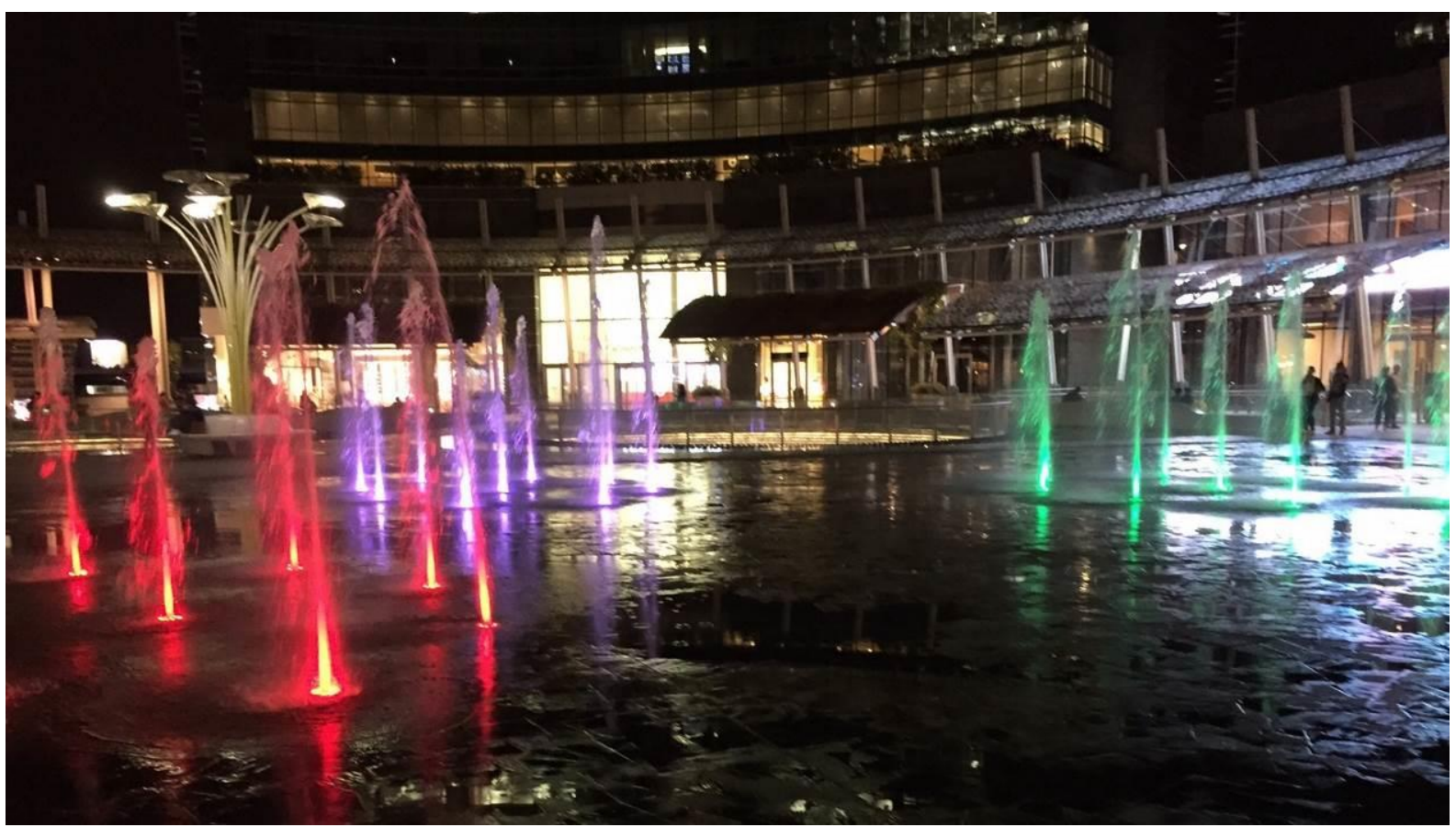

Figure 1. Fountains in Piazza Gae Aulenti, Milan. Source: personal photo

\section{The Game as the Basis of the Decision-Making Processes: the Game Theory}

However, the game can be intended also as an element that represents the process of interaction among people living in a specific territory. For example, the mathematical Game Theory of von Neumann and Morgenstern, 1944 describes the processes of interaction that aim to an individual and/or collective decision.

The focus of this theory is the study of the outcomes of the different people behaviours, by identifying the methods and the models which describe all the possible situations created by the interaction among people and the related behavioral strategies. So, in this theory, the "game" represents an effective metaphor referring to the process of interaction among people (the "players"), who, starting from their preferences and using the acquired information, do actions in order to reach a result, that is a benefit. Generally they need to solve a problem. The models which describe all the possible situations concerning the interaction among different people, can be applied in many areas (e.g.: biology, economy, political science, etc.) and they can be classified in many typologies.

For example, the "cooperative game" is applied when all the players work together in order to reach a common goal and when the collaboration among all the different players is more convenient than playing individually and/or forming an alliance with only a part of the players. In this way, all the participants receive an high value from the collaboration. On the contrary, the "non-cooperative game" is applied when the different players play individually and they intend to reach personal outcomes.

Considering these elements, it is possible to apply the "game" metaphor during the interactions among people aspiring to transform the urban environment. The latter can be considered as the "game context" of this work and the people living in the territory can be intended as the players of this game. They make choices consistent with the possible resources and strategies in a well defined moment. In this sense, the goal of the game can be identified in achieving a higher level of livability in the territory, so the decision making process at the basis of the game involves all the people living in the territory and it aims to that. The outcome is the creation of areas (but, more in general, urban services) on a human scale. It means, for example, that all the architectural elements of the territories are mould, making them more "usable". This process describes in a more simple and direct way the processes of emergence of needs, intentions, and then new properties, belonging to the urban environment. 
According to the Game Theory, in the urban environment the game could be considered as a "cooperative game", since the players share spaces and services, and for this reason they have a shared interest. Moreover, they have a shared information, that represents an important tool in the decision making process. This game could also be considered as a "non-zero-sum game", since the achievement of the interest shared among the players, an element that declares the end of the game, leads to an increase of the value. Indeed, at the end of the game, the resources employed will be optimized and they will produce a value greater than their sum. However, the players have different characteristics, since everyone plays a role with specific, private, and sectoral needs, intentions, and objectives, and in most cases they differ from needs, intentions, and objectives of the other players. For this reason, this game could be considered as an "asymmetric game", because the specific "role" of the single player represents an important variable in the game process and it influences the related strategies.

\section{NON-VERBAL LANGUAGES AS PERFORMATIVE “UTTERANCES" IN URBAN ENVIRONMENT}

In the urban environment, the processes of interaction among people come both from the verbal language, that leads to specific actions (for example: a typical co-design session in which different people come together with the purpose of transforming the urban environment), and from non-verbal languages. Indeed, the different forms of the non-verbal communication, that are the paralinguistic system, the kinesic system, the proxemics, and the haptic, play an important role in transforming the environment: they represent some tools of "relation" among people which structure the spaces. According to Watzlawick et al., 1971 every act of communication has both a content and a relationship aspect: the first focuses on the meaning, the second focuses on the relationship among the interlocutors. In this sense, the non-verbal languages are important carriers of the significance of these relationships.

The gestures among people who share the spaces for transport and mobility within the urban environment are an example of these concepts. The different "users" of the roads, indeed, communicate primarily through non-verbal languages, which are used in order to organize the movement of pedestrians, motorists, drivers, cyclists, etc. Another example is the proxemics, which concerns the distance that a person puts between himself and the others. So, a high distance between people who share a place denotes a low social interaction, which in turn influences the mode of organization of the urban space.

These examples have not only immediate effects on the architectural elements of the urban space. Indeed, in the first case the road users simply understand the movements of the other people, in the second case they communicate a larger or smaller openness to the people who share the same environment. However, they contribute in structuring the environment and the presence of people inside.

Moreover, the organization of the space is intended as a mirror of the social structure, according to the power relations of the territory (for example, see: Ibrahim et al., 2010).

So, we sustain that also the self-organization of the social relationships and the relations of interaction among people living in a territory can mould the places and their architectural elements. For this reason, we can affirm that these interaction processes are based on performative functions.

Indeed, as defined by Austin, 1962 and Searle, 1970, the performative function of a sentence creates something. In the same way, the social interactions create or re-create the architectural elements of the urban space. The latter is transformed in this way. As we said, these performative elements can be based not only on the verbal language, but also on non-verbal languages (first of all the proxemics and the kinesics). Indeed, they are direct, quick, punctual, and conventionally recognized, and for this reason they are more effective than oral or written languages in producing real and visible outcomes and in identifying people needs and desires. A basic example of these processes is the use of formal architectural elements with an aim different from the motivation for which it was created. For 
example, in our urban environments the use of a staircase as seats can mean that people want to structure their proxemics in a way different from those that the architecture allows.

\section{GAME-BASED INTERACTIVE SYSTEMS FOR THE URBAN TRANSFORMATION}

As the non-verbal languages are an important element for the interaction among people living the same urban environment, so they are one of the tools for the interaction and communication within different typologies of games. Some examples are: game applications based on gesture recognition technologies that allow the users to have a direct interface with the systems; the eye contact and facial expressions among the members of the same team that represent an important communication tool in card games; the "hide-and-seek" game that is entirely based on the entry and exit from the intimate space (according to the different areas defined by Halls, 1966 in his "proxemics diagram"); more in general, during a game the paralinguistic system of a player (for example: frequency and tone of voice, rhythm and silence, etc.) reveals important contents concerning the information not shared among the other players.

Considering the meeting points between the languages used in the urban environment, the tools and the methodologies used in game applications, and the centrality of the game in the processes of emergence in the city environment, it is possible to define interactive systems (through both verbal and non-verbal languages) as a tool for designing, realizing, and transforming the architectural elements. Indeed, the game brings people, allowing processes of social interaction (based on verbal and nonverbal languages). In this way, it gives the people the opportunity to make decisions concerning the urban environment, designing, creating and transforming the physichal environment according to their needs and desires. The Figure 2 resumes these relations.

$$
\begin{gathered}
\text { Game } \longrightarrow \text { Social interactions (based on verbal and non verbal languages) } \longrightarrow \text { Decision making } \\
\longrightarrow \text { Self-design } \longrightarrow \text { Transformation of the city }
\end{gathered}
$$

Figure 2. The process that describes how the game can transform the city.

\section{THE GAME AS A META-DESIGN ELEMENT}

In this way, the game becomes a paradigm for designing the architectural elements, that is to say a framework that allows citizens to collaborate in order to adapt the environment to the needs of all the "users" of the city.

This carachteristic refers to the meta-design environment. According to Fischer et al., 2004, the metadesign approach allows to really include the new emergent properties within the system, transforming it. It can be considered as an adaptive process during which the characteristics of the system meet the people needs. It is important to consider the system as an open system, so that it is ready to adopt people demands.

In this sense, it is possible to use the game elements not only to improve the participatory design techniques, but also to strengthen the interaction among people belonging to the community of the territory. In the first case, the game allows users to collaborate in order to mould the spaces of the city, while in the second case it is a tool useful to bring people. Indeed, the game is composed by different elements that can be used individually or in combination in order to co-create and/or bring people. (e.g. experience points, badges, missions, levels, awards, progression bar, gifts, etc.).

In this way, the territory or specific architectural elements of the territory become a metaphor that uses a semantic field belonging to the game environment. This procedure is useful to observe specific city elements under a different point of view. Some examples can be: a square becomes a game table in which the different players, carriers of different instances, collaborate in order to find the organization of the space that satisfies everyone; a neighbourhood becomes a role playing game where all their inhabitants and merchants play a role and complete the assigned "missions", dealing with the territory; 
the whole city becomes a drawing board, where people can imagine a new urban environment; a bus stop becomes a recreation ground that allows to build a relationship among people; etc. Below, these examples will be explained and focused.

\section{A Square Can Become a Game Table}

We can imagine that a Public Administration planned that in a given territory a square will be built, but it hasn't yet been designed nor implemented. This process could be committed to the city users of the territory, who can identify the solutions to implement in line with their needs and desires. The technical feasibility of the identified solutions is ensured by the continuous presence of the PA and the designers. They ask people not simply gather around a table in order to co-design a space, but play and organize the space they live. In details, it is possible to create a collaborative game in which the square is a game table on which different gamers play. They must interact with each other to achieve a common goal. The objective is the design of the square consistently with the needs and demands of all the players. The satisfaction of needs and desires of the players will define the end of the game.

Without considering the specific technical solutions, we can imagine that players have specific "cards", each of which represents specific architectural elements that they would like to see implemented within that space (for example: benches, plants, bicycle racks, etc.). Individual players propose, through these "cards", the elements they desire and they need to meet the favour of the other players, convincing them to accept their proposal. The construction of a story that tells the scenario in which people can use the specific architectural element in the future is fundamental. These metadesign process can be applied not only in designing a square, but also in designing individual architectural elements of the city.

The objective is to obtain a shared vision of the square, to see the future square in the same way. A continuous fixing of the different points of view is the action to do.

The Figure 3 represents a session of the "Planning for Real" technique, where the citizens, considered as players of a game, design together the city they want. This is also a basic example where the game brings people in doing something for their city, but it is possible to think different solutions, that affect the city environment itself and that involve citizens in original ways.

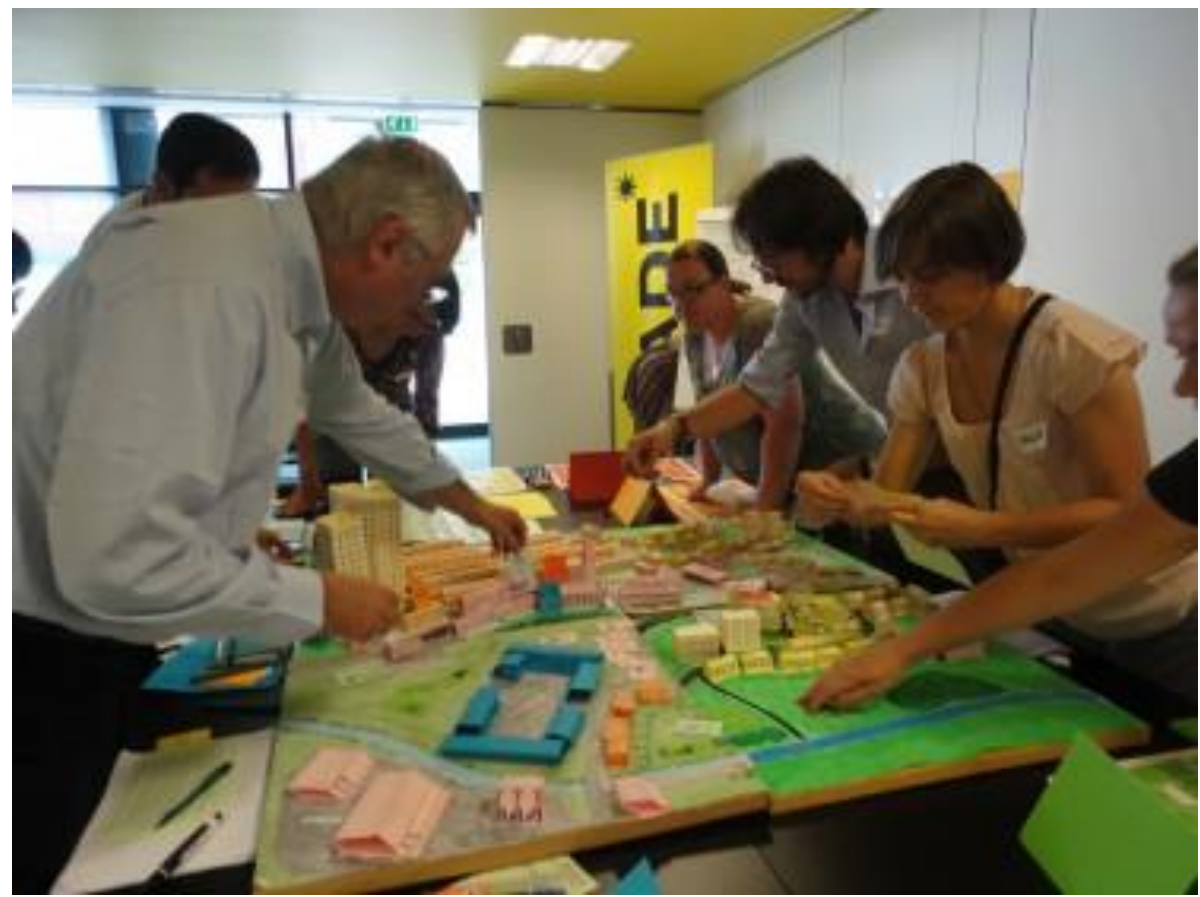

Figure 3. Planning for Real technique. Source: www.planningforreal.org 


\section{A Neighborhood Can Become a Role Playing Game}

In this case, we can imagine a street or a neighbourhood, already built and used, which are the city users themselves to deal with. The actions related to this employment can concern all the aspects of the territorial care or only some of these. Also in this case the presence of the Public Administration is important, since it allows to define the boundaries of possibilities offered to the city users and to check the development process. Considering that the management and the organization of this territory are completely or partly entrusted to the care of people, they always have a territory in line with their own needs and which is useful for those who live there. In this second example, the city users, who are the players of this game, after identifying the objectives to be achieved (a process that could be carried out for example through a process similar to that described in the previous paragraph) in accordance with the Public Administration, can define the specific tasks to be assigned to the single players.

For example, each of these will do actions, which can be defined "missions", consistent with his/her defined "role" in the game. Some possible roles are: the responsible of green spaces, the road manager, the responsible for pollution and waste, the responsible for security, the responsible for public infrastructures, and the budget manager. A possible scenario: the responsible of green spaces will decide the trees to be planted in a park, he/she will clean the green areas, etc., and in doing so he/she will face with the budget manager. It is possible not only to identify single players for single areas, but also a team of players responsible of single areas. The result will be obtained if each player (or each team) will reach individual goals (if he/she will carry out his/her missions) so, if all the players perform them, the outcome is achieved.

As already noted, in this context the presence of the Public Administration is central, so that the solutions are realistic and they respect the technical and structural needs of the territory. Indeed, in this example the specific game elements concern the role playing game, since citizens/players play specific roles and this dimension is the central one. In this sense, the Public Administration can be intended as a "master" or a "narrator", who will answer questions of players and will ensure the players make decisions consistent with specific conditions. Moreover, this framework can represent a good opportunity for the involvement of the Public Administration in the processes of self-organization of the citizens. Indeed, these processes are nowadays already existing but they are still unstructured. On the contrary this process can take a real advantage for the entire territory; just think the need of street artists to have spaces of expression and the need of Public Administrations to regenerate public places.

\section{The Whole City Becomes a Drawing Board}

This solution can be implemented if the players have to identify specific needs and/or problems of the territory, inciting them to imagine a new urban environment in which they can "delete" the element or the characterstics really present and "add" new elements or characterstics. In this way, the city can be intended as a drawing and the single player as a draftsman who can create new things. So, it will be possible to identify the difference between the real and the "pictured" situation.

The Figure 4 represents an example of this process. The "Gulliver Table" can be considered as a "wide sheet to fill". It changes its use and its relation with users; for example it can be a bench or a table, but it can also become a shelter, a playround, etc. 


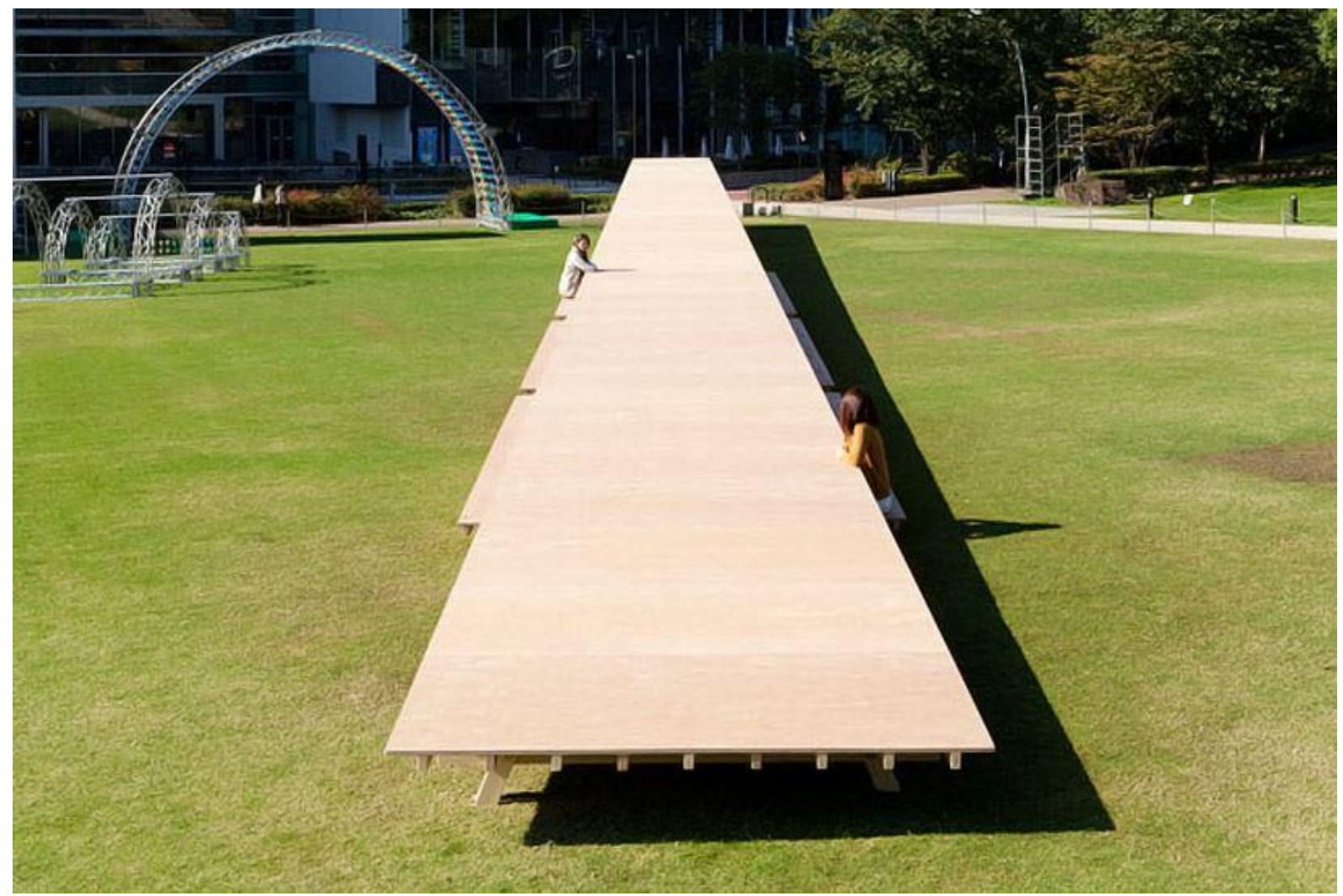

Figure 4. The Gulliver Table, Tokyo. Source: www.designboom.com

\section{A Bus Stop Becomes a Recreation Ground}

In this example, the focus is not on designing city elements, but on creating a relationship among city users. Indeed, the game is a highly sociable activity that allows players also to meta-communicate, that is to say to focus on their relationship rather than on the content of this relationship. During the "use" of the territory, it is possible to occupy the interstices of time and spaces of people in order to strengthen the sense of belonging to a community, the first step for their engagement in building the territory in which they live. These occasions have the aim to focus the attention of people on the same topic, leading them to interact. For this reason, the importance is not so much on reaching a specific goal of the game, but on the relational setting. In this context, the non-verbal languages are the most effective means of communication, since they represent the relation among people more than verbal languages. They represent a possibility, declined in different ways, that leads to activate all the processes for the creation and the regeneration of the city elements.

The Figure 5 represents a good example of this process. In Piazza Gae Aulenti, Milan, there are some tubes that connect different spaces and people. Therefore, passersby can get in touch with other people, where the value of the established relation is more important than the conveyed content. 


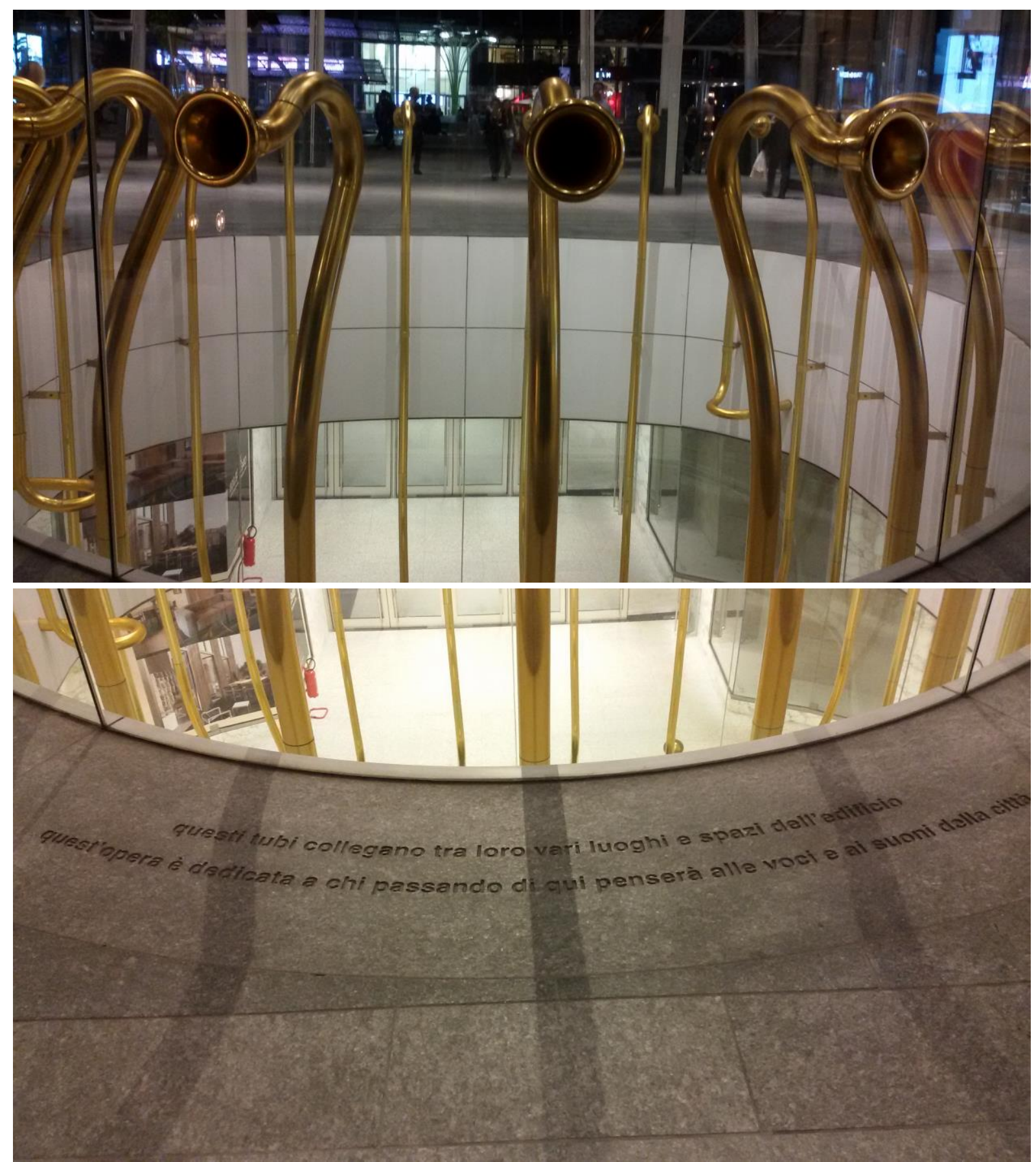

Figure 5. Tubes connecting spaces and people in Piazza Gae Aulenti, Milan. Translation of the second photo: "These tubes connect different places and spaces of the building. This work is dedicated to those who, passing through this place, will think the voices and sounds of the city". Source: personal photo.

In these examples, the game is considered as a meta-design framework that allows to use verbal and non-verbal languages in order to co-create architectural elements, to transform the urban environment and to build a relationship. Bateson, 1972 defines this element a meta-structure. It means that the game does not define the specific elements of the design process, but it provides a possible path that can be traveled. It is a framework of design options to be defined. 
For example, the game as a meta-structure does not define the typology of solutions to be adopted. However, it might be possible to create indicatively two typologies of solutions, which can focus on the contents (it is possible to produce something) or relation (it is possible to bring people): the physical solutions, that concern the installation of elements for co-creation, transformation and interaction in the real environment and the digital solutions that concern the creation of digital applications that have the same objective. In both cases, these solutions have to allow citizens to play in the real and/or digital urban environment, simultaneously or not with other players, so that they leave more or less visible traces, that, related to the others, design or create new spaces of the city.

In our future work we are going to focus on some of these solutions. So, we are going on the second step of the process. Indeed, if in this work we have defined a framework for the design in the next one we will focus on the application of game elements in defining a solution that people can use in order to communicate each other, to create and re-create the environment (the third level of the process).

\section{CONCLUSIONS: THE SYSTEMIC CONTINUITY AMONG GAME, SOCIAL SYSTEMS AND ARCHITECTURAL ELEMENTS}

In the described situation, it is possible to identify a systemic continuity (non-separability) among game, social systems, and architectural elements. Indeed, the real organization of the social system is the basis of the specific game organization, that is to say that the resources available in the game and the possible actions to perform need to be realistic. At the same time, on the basis of this organization, resources, and needs all the architectural elements are realized and they predispose people to specific usages, that can influence the social systems.

\section{REFERENCES}

Alexander, C., Ishikawa, S. \& Silverstein M. (1977). A Pattern Language: Towns, Buildings, Construction. Oxford University Press, New York.

Austin, J. (1962). How To Do Things with Words. Oxford University Press, New York.

Bateson, G. (1972). Steps to an Ecology of Mind: Collected Essays in Anthropology, Psychiatry, Evolution, and Epistemology. University of Chicago Press, Chicago.

De Certeau, M. (1990). L'invention du quotidien, Gallimard, Paris.

Fischer, G., Giaccardi, E. (2006). "Meta-Design: A Framework for the Future of End User Development". In: End User Development - Empowering people to flexibly employ advanced information and communication technology (Lieberman, H., Paternò, F., Wulf V.). Kluwer Academic Publishers, Dordrecht.

Huizinga, J. (1971). Homo Ludens. Beacon Press, Boston.

Ibrahim, M., Jahnkassim, S., Idris, M. et al. (2010). Architecture as a Reflection of Social Structure. A Reminiscence of the Suleymaniye Complex of Istanbul. Kulliyyah of Architecture and Environmental Design, Malaysia.

Maturana, H. R., Varela, F. J. (1980). "Autopoiesis and Cognition. The Realization of the Living". Boston Studies in the Philosophy of Science, 42.

Mead, G.H. (1934). Mind, Self and Society. The University of Chicago Press, Chicago.

Minati, G. (2001), Esseri Collettivi, Apogeo Scientifica, Milan.

Minati, G. (2008). Systemics and Emergence for Architecture. In memory of Professor G. Ciribini.

Searle, J.R. (1970). Speech Acts: An Essay in the Philosophy of Language. Cambridge University Press, Cambridge.

Throgmorton, J., Eckstein, B. Desire Lines: The Chicago Area Transportation Study and the Paradox of Self in Post-War America. Literary and Visual Representations of Three American Cities, 1870s to 1930. A project web site of the 3 Cities Project of the Universities of Nottingham and Birmingham, United Kingdom. http://www.nottingham.ac.uk/3cities/throgeck.htm 
Turner, V. (1982). From Ritual to Theatre. The Human Seriousness of Play. Performing Arts Journal Publications, New York.

Watzlawick, P., Beavin J.H., Jackson Don D. (1971). Pragmatica della comunicazione umana. Astrolabio, Roma.

Winnicot, D.W. (1971). Playing and Reality. Tavistock Publications, London.

von Neumann, J. \& Morgenstern, O. (1944). Theory of Games and Economic Behavior. Princeton University Press. 